\title{
Therapeutic Options for Coronavirus Disease 2019 (COVID-19): Where Are We Now?
}

\author{
Esther Y. Bae ${ }^{1}(1) \cdot$ James M. Sanders ${ }^{1} \cdot$ Meagan L. Johns ${ }^{1} \cdot{\text { Kevin } \text { Lin }^{2} \cdot \text { Jessica K. Ortwine }}^{3} \cdot$ Wenjing Wei $^{3}$. \\ Norman S. Mang ${ }^{3}$. James B. Cutrell ${ }^{4}$
}

Accepted: 22 October 2021 / Published online: 11 December 2021

(c) The Author(s), under exclusive licence to Springer Science+Business Media, LLC, part of Springer Nature 2021

\begin{abstract}
Purpose of Review Rapidly evolving treatment paradigms of coronavirus disease 2019 (COVID-19) introduce challenges for clinicians to keep up with the pace of published literature and to critically appraise the voluminous data produced. This review summarizes the clinical evidence from key studies examining the place of therapy of recommended drugs and management strategies for COVID-19.

Recent Findings The global magnitude and duration of the pandemic have resulted in a flurry of interventional treatment trials evaluating both novel and repurposed drugs targeting various aspects of the viral life cycle. Additionally, clinical observations have documented various stages or phases of COVID-19 and underscored the importance of timing for the efficacy of studied therapies. Since the start of the COVID-19 pandemic, many observational, retrospective, and randomized controlled studies have been conducted to guide management of COVID-19 using drug therapies and other management strategies. Large, randomized, or adaptive platform trials have proven the most informative to guide recommended treatments to-date. Antimicrobial stewardship programs can play a pivotal role in ensuring appropriate use of COVID-19 therapies based on evolving clinical data and limiting unnecessary antibiotics given low rates of co-infection.

Summary Given the rapidly evolving medical literature and treatment paradigms, it is recommended to reference continuously updated, curated guidelines from national and international sources. While the drugs and management strategies mentioned in this review represent the current state of recommendations, many therapies are still under investigation to further define optimal COVID-19 treatment.
\end{abstract}

Keywords COVID-19 $\cdot$ SARS-CoV-2 $\cdot$ Immunomodulators · Antivirals $\cdot$ Anticoagulation $\cdot$ Antimicrobial stewardship

\section{Introduction}

This article is part of the Topical Collection on Tropical, Travel and Emerging Infections

Esther Y. Bae

esther.bae@utsouthwestern.edu

1 Department of Pharmacy, University of Texas Southwestern Medical Center, Dallas, US

2 Department of Pharmacy, Ochsner Medical Center, New Orleans, US

3 Department of Pharmacy, Parkland Hospital, Dallas, US

4 Department of Medicine, Division of Infectious Diseases and Geographic Medicine, University of Texas Southwestern Medical Center, Dallas, US
Severe acute respiratory syndrome coronavirus 2 (SARSCoV-2), the causative agent of coronavirus disease 2019 (COVID-19), was first identified in Wuhan, China, in late 2019 and since has resulted in a pandemic with over 237 million cases and 4.8 million deaths as of October 2021 [1]. The magnitude and duration of the pandemic have resulted in a flurry of interventional treatment trials evaluating both novel and repurposed drugs targeting various aspects of the viral life cycle [2]. One of the greatest challenges for clinicians in the treatment of COVID-19 has been keeping up with the pace of published literature and critically appraising the voluminous data produced. Given rapidly evolving treatment paradigms, it is highly recommended to reference continuously updated, curated guidelines from national and 
international sources such as the US National Institutes of Health (NIH) and World Health Organization (WHO) [3•, 4•]. The following review summarizes the recommended COVID-19 therapeutic options as of October 2021 in the context of a clinical approach based on disease severity and stage.

\section{Clinical Approach to COVID-19 Management}

Clinical approaches to COVID-19 have primarily categorized patients according to disease severity although the specific categories vary across guidelines and clinical trials [3•]. Asymptomatic or pre-symptomatic infection includes a positive virologic test by nucleic acid amplification or antigen in the absence of symptoms. Mild disease includes other COVID-19 symptoms without clinical or radiographic evidence of lower respiratory disease. Moderate disease includes clinical or radiographic evidence of lower respiratory disease and an oxygen saturation $\left(\mathrm{SpO}_{2}\right) \geq 94 \%$ on room air (RA). Severe disease includes evidence of lower respiratory disease and $\mathrm{SpO}_{2}<94 \%$ on RA or other markers of respiratory insufficiency. Critical illness includes respiratory failure, septic shock and/or multi-organ dysfunction. Guidelines and interventional trials have stratified patients based on disease severity and treatment location (hospitalized vs. non-hospitalized) with the understanding that a patient's clinical status may change over time.

Additionally, clinical observations have documented various stages or phases of COVID-19 and underscored the importance of timing for the efficacy of studied therapies (Fig. 1) [5, 6]. Simplistically, there is a pre-exposure and incubation period, followed by an early viral phase when most symptoms are due to viral replication. Then, in some individuals, they progress into a hyperinflammatory phase

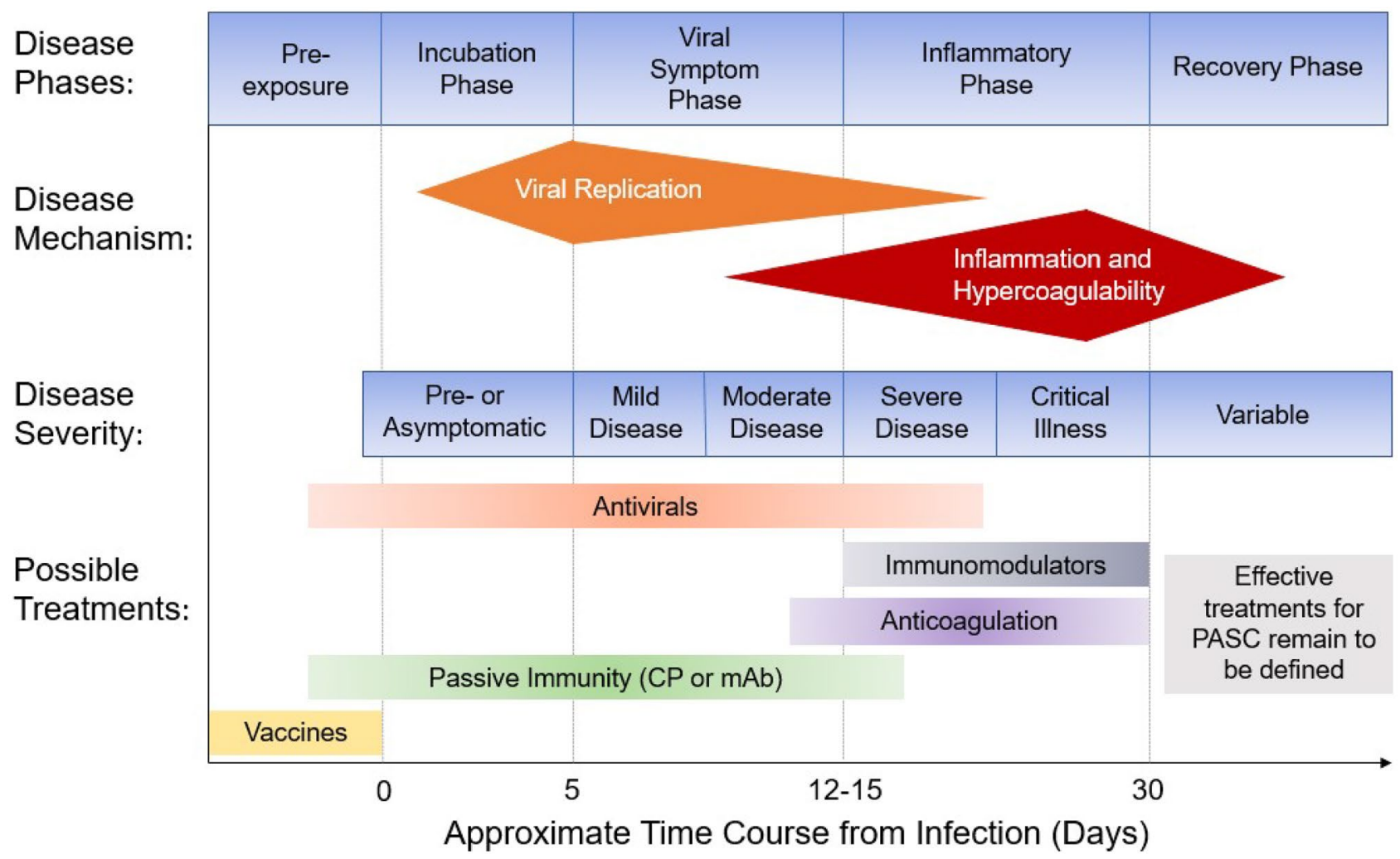

Fig. 1 Clinical management approach to COVID-19 based on disease phase and severity. Clinical observations from patients with COVID19 have identified various disease phases from the pre-exposure period through a viral symptom and inflammatory phase and ending with a recovery phase. Early phases are marked by symptoms attributable to viral replication whereas later phases appear to be driven more by host inflammatory and immune responses in addition to a hypercoagulable state. Determination of the disease phase and sever- ity of a patient may inform timing of specific COVID-19 therapies to maximize their efficacy and minimize toxicity. $\mathrm{CP}$ convalescent plasma, mAb monoclonal antibody therapy (against SARS-CoV-2), PASC post-acute sequelae of COVID-19. Adapted from: Gandhi RT, Lynch JB, Del Rio C. Mild or Moderate Covid-19. N Engl J Med. 2020;383(18):1757-66. doi:10.1056/NEJMcp2009249. By permission of Massachusetts Medical Society. Copyright (C) 2021. 
when host immune and inflammatory responses drive the disease pathogenesis. Finally, a subset of patients, irrespective of disease severity, enter a prolonged "tail phase" now referred to as post-acute sequelae of COVID-19 (PASC). While this heuristic can prove useful in targeting the timing of specific interventions, caution must be exercised since the criteria for identifying the current stage and pace of disease evolution in a specific patient remain poorly defined.

\section{Remdesivir}

Remdesivir is a prodrug that is metabolized to a nucleoside triphosphate analogue to inhibit viral ribonucleic acid (RNA) polymerase by inducing delayed chain termination. It has broad activity against RNA viruses, including SARS-CoV-2, SARS-CoV-1, and Middle Eastern respiratory syndrome coronavirus (MERS-CoV) [7, 8]. Animal studies in SARS-CoV-2 supported its efficacy in treatment during early phases of infection, and several randomized controlled trials (RCTs) have been conducted to evaluate the clinical efficacy of remdesivir [7,9].

In May 2020, the US Food and Drug Administration (FDA) approved remdesivir via emergency use authorization (EUA) for clinical use based on the SIMPLE-Severe trial and a preliminary report of the ACTT-1 trial. ACTT-1 was a randomized, double-blind, placebo-controlled trial that evaluated the clinical efficacy of remdesivir for 10 days in hospitalized patients with COVID-19 [10]. In its final report, patients who received remdesivir had a reduced time to recovery by 5 days and were more likely to have clinical improvement at day 15 compared to placebo (Table S1). Reduced time to recovery was most apparent in patients receiving low-flow oxygen and with symptom onset of 10 days or less. In contrast, DisCoVeRy was an open-label, multicenter, randomized controlled trial which found no difference between standard of care with or without remdesivir on improved clinical status at day 15 in hospitalized patients requiring oxygen support who were symptomatic for more than 7 days [11]. However, a direct comparison of the time to clinical improvement finding from ACTT-1 is not possible as DisCoVeRy utilized a slightly different endpoint, ordinal scale, and had twice as many patients who received concomitant corticosteroids. Similarly, Wang and colleagues did not find reduced time to recovery in a similar study involving mostly patients requiring low-flow oxygen although the study was potentially underpowered due to early termination [12]. The SIMPLE-Severe trial found no difference in clinical efficacy between 5-day and 10-day course of remdesivir in patients with $\mathrm{SpO}_{2} \leq 94 \%$ on RA or supplemental oxygen, supporting the efficacy of the shorter 5-day course [13].
Data supporting the benefit of remdesivir in hospitalized patients not requiring oxygen are lacking. The SIMPLEModerate trial demonstrated inconsistent results regarding improved clinical status on day 11 between 5-day and 10-day remdesivir therapies in hospitalized patients not requiring supplemental oxygen [14]. Remdesivir also failed to demonstrate statistically significant benefit in subgroup analyses of patients on RA in both the ACTT-1 and SOLIDARITY trials. Thus, the routine use of remdesivir is discouraged in patients who do not require oxygen $[3 \bullet, 10,14,15]$.

Progression to the use of high-flow oxygen (HFO), mechanical ventilation (MV), or extracorporeal membrane oxygenation (ECMO) may be indicative of underlying development of COVID-19-associated hyperinflammatory syndrome [16]. Because hyperinflammation typically occurs later in the disease course when viral replication is waning, the role of antiviral agents like remdesivir at this stage is less clear [17, 18]. Interestingly, DisCoVeRy and Wang et al. both found that remdesivir was no better than standard of care (SOC) in reducing measured viral loads. The median time to symptom onset in DisCoVeRy was 9 days, which was comparable to ACTT-1 and other RCTs. This supports the theory that initiating antiviral therapy earlier in the disease course, potentially closer to peak viral replication, is paramount to successfully reducing viral burden and improving clinical outcomes. Remdesivir did not demonstrate a difference in time to recovery in a subgroup analysis of patients requiring HFO or non-invasive ventilation (NIV) in ACTT-1 although the small numbers may lack power needed to detect a difference (rate ratio for recovery 1.09 [95\% confidence interval [CI], 0.76 to 1.57]) [10]. Overall, there are insufficient data in this patient population for definitive treatment recommendations due to small subgroups, confounding factors in disease severity, and inconsistent trends of clinical efficacy $[9,13]$.

No RCTs have demonstrated a statistically significant reduction in mortality with remdesivir. The SOLIDARITY trial is the largest published RCT among hospitalized patients and found no difference in the rate of in-hospital mortality between 10-day remdesivir and SOC (Table S1) [19]. Similarly, the DisCoVeRy trial also showed no improvement in 28-day all-cause-mortality. Although criticized for their open-label designs, the mortality outcome measures were unlikely to have been affected. Additionally, no difference in length of stay or progression to MV was found. In ACTT-1, mortality was not significantly different between remdesivir and placebo, and similar findings were seen by Wang and colleagues (Table S1) [10, 12].

Remdesivir is currently FDA approved for the treatment of COVID-19 in hospitalized patients [20]. Although remdesivir is the only antiviral agent which has demonstrated clinical efficacy in the treatment of COVID-19, current data do not definitively identify which patients would most benefit. In addition, the lack of survival benefit coupled with the 
significant cost and potential for toxicity should be taken into consideration. Remdesivir should be utilized in conjunction with guideline recommendations when making individualized treatment decisions.

\section{Passive Immunity (Monoclonal Antibodies and Convalescent Plasma)}

\section{Monoclonal Antibodies}

Monoclonal antibodies (mAbs) provide passive immunity against SARS-CoV-2 via direct administration of SARSCoV-2 antibodies, resulting in a more rapid viral neutralization than occurs naturally upon viral exposure. The ability to administer specific antibodies targeting clinically significant binding sites on the spike protein makes mAbs one of the preferred therapeutic agents.

Phase 2 trials of casirivimab/imdevimab and bamlanivimab/etesevimab in non-hospitalized adults demonstrated greater decreases in SARS-CoV-2 mean viral load change from baseline with either $\mathrm{mAb}$ combination compared to placebo [21-23]. More importantly, Weinreich and colleagues found that administration of a single dose of either 2400-mg or 8000-mg of casirivimab/imdevimab decreased medically attended visits or hospitalizations through day 29 by $50 \%$ when compared to patients receiving placebo [21]. Similarly, Gottlieb and colleagues reported significant reductions in hospitalizations or emergency department (ED) visits at day 29 in the bamlanivimab/etesevimab arm compared to placebo (Table S1) [22].

Subsequent phase 3 trials of these two agents and an additional third agent, sotrovimab, evaluated clinical outcomes among outpatients at highest risk for progression to severe COVID-19. The casirivimab/imdevimab study enrolled 4057 adult outpatients with COVID-19 and at least one risk factor for severe disease [24]. Hospitalization or all-cause mortality through day 29 was significantly lower among patients receiving $1200 \mathrm{mg}$ or $2400 \mathrm{mg}$ of casirivimab/imdevimab (1.0\% and $1.3 \%$, respectively) compared to matched placebo groups $(3.2 \%$ and $4.6 \% ; p<0.05$ for both comparisons). Similar findings were reported with an 8000-mg dose as well; however, this arm was discontinued once phase 2 data reported similar antiviral and clinical outcomes to the 2400mg dose. Likewise, the phase 3 portion of the BLAZE-1 trial evaluating bamlanivimab/etesevimab in patients with COVID-19 at high-risk for severe disease revealed significantly lower hospitalization or mortality rates at day 29 of $2.1 \%$ for patients receiving doses of $2800 \mathrm{mg} / 2800 \mathrm{mg}$ compared to $7.0 \%$ of patients receiving placebo $(p<0.001)$. Importantly, there were no deaths in patients receiving either dose of bamlanivimab/etesevimab [25]. Lastly, interim results from COMET-ICE, the phase 3 trial of the singular monoclonal antibody agent sotrovimab, demonstrated fewer instances of hospitalization or death among adult outpatients with at least one prespecified risk factor or comorbidity for severe COVID-19 who received sotrovimab (1\%) compared to placebo $(7 \%, p=0.002)$ [26].

Casirivimab/imdevimab has also been studied as a treatment option for hospitalized patients with COVID-19 [27]. Administration of 8000-mg of casirivimab/imdevimab significantly decreased 28-day mortality among patients who were seronegative for SARS-CoV-2 antibodies at baseline, but, importantly, had no impact on mortality in the overall population. Bamlanivimab monotherapy was also studied for this indication, similarly showing no benefit in sustained recovery or all-cause mortality compared to placebo [28].

Casirivimab/imdevimab and bamlanivimab have also both shown benefit in preventing symptomatic SARSCoV-2 infection among persons having consistent close contact with COVID-19-infected individuals. In an evaluation of seronegative and SARS-CoV-2-negative patients with household exposure to an infected individual, O'Brien and colleagues reported $29 \%$ of patients receiving casirivimab/ imdevimab and $42 \%$ of patients receiving placebo went on to develop symptomatic infection $(p=0.038)$ [29]. Cohen and colleagues reported similar findings after administration of bamlanivimab monotherapy to residents or staff of skilled nursing or assisted living facilities, with $8.5 \%$ of patients developing symptomatic infection compared to $15.2 \%$ of patients receiving placebo $(p<0.001)$ [30].

The spike protein mutations observed with the SARSCoV-2 variants have been shown to impact mAb binding to various degrees. Casirivimab/imdevimab and sotrovimab retain activity against all current SARS-CoV-2 variants of concern. Conversely, bamlanivimab/etesevimab has decreased or negligible activity against some variants but is expected to retain activity against the Delta (B.1.617.2) variant which is currently (as of October 2021) the most prevalent circulating variant [31-33].

\section{Convalescent Plasma}

Convalescent plasma (CP) is collected from COVID-19 recovered patients and administered to those with active infection. The proposed primary benefit of CP occurs via pathogen neutralization through antibodies; however, other mechanisms may exist as well. Based on the use of CP in other infections, including those caused by SARS-CoV-1, early interest in CP sparked extensive clinical use, including establishment of a US-based registry that enrolled over 105,000 patients as of March 2021 [34]. The FDA granted EUA for CP in August 2020 based on potential benefit and antibody-dose response effects from an observational analysis of the previously mentioned registry. A subsequent publication demonstrated a mortality benefit associated with 
transfusion of "high-titer" CP (to approximate anti-SARSCoV-2 immunoglobulin G [IgG] titers $>1: 2560$ ) compared to low-titer $\mathrm{CP}$ in hospitalized patients not requiring $\mathrm{MV}$ [35]. However, the retrospective, observational nature of the data and lack of controls limited interpretation, and subsequent RCTs have failed to show consistent benefit. In February 2021, the EUA was updated to limit use of high-titer CP to hospitalized patients early in their disease course or with impaired humoral immunity [36].

The largest RCT to-date was the UK-based RECOVERY trial. The CP arm of this study randomized hospitalized patients $(N=11,558)$ to receive either $\mathrm{CP}$ (with neutralizing $\mathrm{Ab}$ titer $>1: 100$ ) plus SOC or SOC alone and found no difference in 28-day mortality, probability of hospital discharge, or progression to MV or death in those not intubated at baseline [37]. Similarly, a systematic review and meta-analysis of four peer-reviewed RCTs and six other publicly available RCT data sets (including RECOVERY) found no reduction in all-cause mortality or other benefits from $\mathrm{CP}$ compared to placebo [38]. Current NIH guidelines recommend against the use of low-titer CP for any patients or the use of high-titer $\mathrm{CP}$ for any immunocompetent patients on MV or those who are hospitalized outside of a clinical trial [ $3 \bullet$. Per the guidelines, insufficient data exist to recommend high-titer $\mathrm{CP}$ in immunocompromised patients or non-hospitalized patients. Indeed, early high-titer (IgG $>1: 1000) \mathrm{CP}$ was shown to be effective at preventing progression to severe disease in older non-hospitalized adults with mild disease if given within $72 \mathrm{~h}$ of symptom onset [39].

Overall, CP appears to be relatively safe, with $<1 \%$ rates of serious adverse events reported [40]. Transfusion or allergic reactions, and theoretical deleterious immunomodulatory effects of autoantibodies present in $\mathrm{CP}$ should remain a consideration. With the lack of RCT efficacy data and difficulty measuring neutralizing $\mathrm{Ab}$ titers commercially, $\mathrm{CP}$ presently does not have a major role in COVID-19 management, particularly in situations where SARS-CoV-2 mAbs are available.

\section{Immunomodulators (Corticosteroids, Interleukin-6 Receptor Antagonists, Baricitinib)}

COVID-19-mediated immunomodulation and inflammatorymediated lung injury are potential therapeutic targets to quell the "immune-mediated storm" elicited by the virus [41]. SARS-CoV-2 expresses proteins that inhibit type 1 interferon production, resulting in a delayed antiviral response, rapid viral replication, and recruitment of monocytes/macrophages and neutrophils to lung parenchyma [42]. The recruited inflammatory cells produce cytokines (e.g., interleukin-6
(IL-6)) via cell transduction pathways (e.g., Janus kinase (JAK) 1/JAK2) that trigger a form of cytokine release syndrome (CRS), making immunomodulators attractive options for treatment of COVID-19. However, the anti-inflammatory effects must be balanced with potential negative effects of enhanced viral replication, secondary infections, and adverse drug effects.

\section{Corticosteroids}

Early in the pandemic, clinical guidelines discouraged routine corticosteroid use based on previous studies demonstrating associated increases in viral replication or mortality in the treatment of other novel coronaviruses or influenza [3•, $4 \bullet]$. However, a better understanding of the pathophysiology underlying COVID-19 and more robust clinical trial evidence have clarified the role of corticosteroids in severe COVID-19 [41].

The corticosteroid arm of the RECOVERY trial comparing dexamethasone to SOC produced the most paradigmshifting COVID-19 trial results to date. The study demonstrated a mortality reduction ( $22.9 \%$ vs. $25.7 \%$; age-adjusted risk ratio 0.83 [ $95 \% \mathrm{CI}, 0.75$ to 0.93 ]; $p<0.001$ ), with the most pronounced effects seen in those requiring MV or supplemental oxygen at the time of randomization (Table S1). Notably, dexamethasone did not reduce mortality in patients not on supplemental oxygen at randomization, with a potential trend towards harm [43•].

Based on the RECOVERY trial results, several other clinical trials were terminated early for ethical concerns regarding withholding corticosteroid treatment (Table S1). However, a preplanned, prospective meta-analysis of seven RCTs of critically ill COVID-19 patients showed a reduction in 28-day all-cause mortality with corticosteroids compared to SOC or placebo, $32 \%$ vs. $40 \%$ (odds ratio [OR] 0.66 [95\% CI, 0.53 to $0.82]$ ), respectively. The RECOVERY trial contributed $57 \%$ of the weight in the analysis, and when excluded, the OR for the primary outcome was 0.77 (95\% CI, 0.56 to 1.07) [44].

Due to heterogeneity in available trials, several questions remain regarding the use of corticosteroids: optimal corticosteroid agent, dose, and duration [44]. The benefit of additional corticosteroids for patients already on chronic corticosteroids is unknown as these patients have been excluded or not analyzed in existing trials (Table S1). Administration of inhaled budesonide has shown a clinical benefit for the management of outpatients, but confirmatory studies are needed [45]. Adverse effects due to steroids, particularly increased rates of secondary bacterial and fungal infections, remain a concern.

\section{Interleukin-6 Receptor Antagonists}

Interleukin-6 (IL-6) receptor antagonists have been investigated in COVID-19 given their potential role in mitigating the CRS that contributes to severe or critical disease. Eight 
RCTs evaluating tocilizumab in COVID-19 are published with discordant results (Table S1) [46-53]. Only the two largest trials, REMAP-CAP and RECOVERY, showed a mortality reduction $[52,53]$. The smaller trials may have been underpowered to demonstrate a mortality reduction, and those conducted earlier in the pandemic included fewer patients on concomitant corticosteroids compared to REMAP-CAP and RECOVERY, which may have also impacted the study outcome (Table S1). The REMAP-CAP and RECOVERY trials also have higher mortality rates in the SOC arms compared to the other studies, likely indicating a sicker population at enrollment.

REMAP-CAP, a multifactorial, adaptive platform trial comparing tocilizumab or sarilumab to a control group, enrolled patients on HFO or cardiovascular support within $24 \mathrm{~h}$ of intensive care unit (ICU) admission (Table S1) [53]. Interleukin-6 receptor antagonist was associated with increased number of organ support-free days at 21 days and reduced in-hospital mortality ( $27 \%$ vs. $36 \%$; adjusted OR for in-hospital survival 1.64 [95\% CI, 1.25 to 2.14$]$ ).

The RECOVERY trial, comparing the addition of tocilizumab versus SOC alone, is the largest randomized trial published [52]. Hospitalized patients were included and enrolled in a second randomization in the event of clinical disease progression $\left(\mathrm{SaO}_{2}<92 \%\right.$ on $\mathrm{RA}$ or requiring oxygen therapy and C-reactive protein (CRP) $\geq 75 \mathrm{mg} / \mathrm{L}$ ). The study reported a reduction in 28-day mortality with the addition of tocilizumab (31\% vs. 35\%; rate ratio [RR] 0.85 [95\% CI, 0.76 to 0.94$]$ ). Based on evidence from the REMAP-CAP and RECOVERY studies, tocilizumab is recommended in combination with corticosteroids in those recently hospitalized with rapidly increasing oxygen requirements and $\mathrm{CRP} \geq 75 \mathrm{mg} / \mathrm{dL}$ or within $24 \mathrm{~h}$ of ICU admission [3•].

Some areas of uncertainty remain. Limited published evidence is available for sarilumab, as only 48 patients were included in the sarilumab arm of REMAP-CAP [53]. One RCT did not find a significant reduction in time to clinical improvement or in mortality with sarilumab in hospitalized patients requiring supplemental oxygen or ICU admission [54]. Sparse data are available on the safety and efficacy of a repeat dose of tocilizumab and the use of tocilizumab in immunocompromised patients. Lastly, the risk of secondary infections with tocilizumab use is unclear. Reported rates of secondary infections with tocilizumab have been low in RCTs although one retrospective cohort study $(N=994)$ revealed a higher rate of secondary infections ( $34.4 \%$ vs. $10.7 \%)$ [55].

\section{Baricitinib}

Baricitinib is an orally administered, reversible, selective inhibitor of JAK1/JAK2, hypothesized to have beneficial effects on acute respiratory distress syndrome (ARDS) and organ damage caused by SARS-CoV-2. Baricitinib primarily inhibits the cytokine signaling pathways in COVID-19, but it may also have antiviral effects by targeting host cell factors necessary for viral entry [56].

Although several existing trials have evaluated the efficacy of baricitinib, two primary RCTs have been peerreviewed and published. ACTT-2 compared remdesivir plus baricitinib to remdesivir plus placebo in hospitalized adult patients with COVID-19. The primary outcome of time to recovery, defined as discharge from the hospital or hospitalized but not requiring oxygen, was lower in the intervention group compared to the placebo group by one day (Table S1). This benefit was most pronounced in patients with severe COVID-19 requiring HFO or NIV, in whom the addition of baricitinib was more likely to result in clinical recovery. No difference in mortality was seen between groups [57].

Results from a placebo-controlled RCT, COV-BARRIER, demonstrated a mortality benefit with baricitinib plus SOC compared to placebo plus SOC. About $80 \%$ of enrolled patients received a systemic corticosteroid as part of their SOC, but only a minority received the antiviral remdesivir. The primary outcome of disease progression at 28 days was not significantly different between groups. However, 28-day mortality was significantly reduced by $38 \%$ in the baricitinib arm (8\% vs. 13\%; hazard ratio 0.57 [95\% CI 0.41 to 0.78 ]; $p=0.0018$ ). This mortality reduction was seen in all pre-specified subgroups of baseline severity, but similar to ACTT-2, the effect was most pronounced for patients on HFO or NIV [58 $\bullet$.

Based on the data from ACTT-2 and COV-BARRIER, the NIH guideline, as of October 2021, recommends using baricitinib in combination with (1) dexamethasone alone or (2) dexamethasone plus remdesivir for patients who are recently hospitalized, on HFO or NIV, have rapidly increasing oxygen needs, and have increased markers of inflammation [3•]. Based on expert opinion, additional consideration can be made for using baricitinib in patients who are not yet on HFO or NIV but have rapidly increasing oxygen requirements and increased markers of inflammation; however, there is insufficient evidence to delineate which patients in this subgroup would benefit the most from baricitinib. Baricitinib should be discontinued in hospitalized patients who are stable enough for discharge and are no longer requiring supplemental oxygen. Results from multiple ongoing trials are awaited to further define the specific role of baricitinib in COVID-19 treatment, including its efficacy compared to or in combination with other immunomodulatory therapy.

\section{Adjunctive Therapies (Anticoagulation and Prone-Ventilation)}

One of the most debated topics in COVID-19 management is the role of therapeutic and intermediate-dose anticoagulation. The INSPIRATION trial, a multicenter RCT comparing 
intermediate-dose ( $1 \mathrm{mg} / \mathrm{kg}$ subcutaneously daily) to standard dose (40 mg subcutaneously daily) enoxaparin prophylaxis in ICU patients, found no reduction in the 30-day composite rate of venous/arterial thrombosis, ECMO, or mortality (Table S1) [59]. Limitations of the trial included complex dosing strategies in obesity, low overall venous thromboembolism rates, and the use of daily vs. twice-daily dosing. Another RCT including patients with severe illness found no difference in 30-day all-cause mortality with intermediate-dose compared to standard-dose enoxaparin (Table S1). [60]

Results from an international, multiplatform, RCT (REMAP-CAP, ACTIV-4a, ATTACC) were recently published. In this study, enrollment was halted for the ICU cohort when an interim analysis revealed statistical criteria for futility was met (Table S1) [61]. Therapeutic anticoagulation (with unfractionated [UFH] or low molecular weight heparin (LMWH)) compared to thromboprophylaxis did not improve median organ support-free days through day 21 . Results from the interim analysis of the non-ICU, moderately ill cohort $(N=2219)$ revealed an increase in median organ support free days through day 21 with therapeutic anticoagulation (adjusted OR 1.27; [95\% CI, 1.03 to 1.58]) (Table S1) [62]. In January 2021, enrollment was also halted in this cohort based on the data. In contrast, results of the ACTION trial did not show any benefit with therapeutic anticoagulation in a composite endpoint of mortality, duration of hospitalization, or oxygen support at 30 days [63]. This RCT included 615 predominantly moderately ill hospitalized patients. Results from the RAPID trial showed no difference with therapeutic versus prophylactic dose UFH or LMWH in the composite endpoint of death, invasive or non-invasive mechanical ventilation, or ICU admission in moderately ill patients with an elevated D-dimer (Table S1). [64] However, therapeutic compared with prophylactic dose UFH or LMWH in this study revealed a reduction in 28-day mortality. These results suggest that initiating therapeutic anticoagulation in ICU patients requiring organ support may be too late to impact disease pathology. However, initiating early anticoagulation in moderately ill hospitalized patients may impact survival.

Aspirin is being evaluated in large RCTs in hospitalized COVID-19 patients, including REMAP-CAP and RECOVERY [65]. Results from pre-publication for the RECOVERY trial show aspirin (vs. usual care) provides no significant reduction in 28-day mortality (17\% vs. 17\%; RR 0.96 [95\% CI, 0.89 to 1.04]; $p=0.35$ ) [66]. Results from RCTs in outpatients are awaited to determine aspirin's optimal place in therapy [65].

The use of 12 to $16 \mathrm{~h}$ of prone ventilation is recommended for COVID-19 patients with moderate-to-severe ARDS requiring MV (BIIa) [3•, 67]. A systematic review and meta-analysis of five trials revealed a mortality benefit with $12 \mathrm{~h}$ or more of prone ventilation in non-COVID-19 moderate-to-severe ARDS patients requiring MV (RR 0.74 [95\% CI, 0.56 to 0.99]) [68, 69]. There is limited evidence on outcomes with awake prone positioning in nonintubated patients. Observational studies in COVID-19 and non-COVID-19 non-intubated patients have shown it may improve oxygenation [70]. A trial of awake prone positioning to improve oxygenation is recommended in COVID-19 patients with increasing oxygen requirements without an indication for intubation (CIIa) [3•]. The role of adjunctive COVID-19 therapies continues to be debated, and the results of several large RCTs are expected to further elucidate the role of anticoagulation and antiplatelet medications.

\section{Drugs with Unproven Efficacy or Still Under Investigation}

Since the start of the COVID-19 pandemic, many other novel and repurposed drugs have received attention and been studied in clinical trials of various quality and rigor. Many of these drugs have either not proven to have benefit based on the available data in COVID-19 patients or insufficient data to draw conclusions. Table 1 describes proposed mechanism of actions (against SARS-CoV-2) and data from select clinical trials evaluating their role in COVID-19 treatment.

\section{Stewardship Considerations}

Antimicrobial stewardship programs (ASPs) strive to optimize antimicrobial use to curb untoward effects, such as development of multi-drug resistant organisms (MDROs) or Clostridioides difficile infections [71]. Already well-positioned to guide and review appropriateness of antimicrobial use, many ASPs contributed to COVID-19 response efforts in numerous ways: ensuring appropriate use of COVID-19 specific therapies based on evolving clinical data, development of local COVID-19 management guidelines, and allocation protocols for experimental agents (e.g., EUA, compassionate use, or expanded access) [72].

With the sudden arrival of the COVID-19 pandemic, many traditional ASP efforts were diverted to the aforementioned COVID-19 response. In addition, initial uncertainties in COVID-19 management posed serious challenges to frontline providers in judiciously evaluating and administering therapies including antimicrobials. Data now suggest that, unlike with influenza, bacterial co-infections with initial COVID-19 presentation are relatively uncommon $(<4 \%)$ [73-75]. However, antibiotic use was disproportionately high with studies suggesting over two-thirds of hospitalized COVID-19 patients before mid-April 2020 received antibiotics [74]. Unfortunately, this overuse of antibiotics appear to 
Table 1 Proposed mechanism of action and clinical data for drugs still under investigation or of unproven efficacy for COVID-19

Atovaquone

Chloroquine (CQ) or hydroxychloroquine (HCQ) \pm azithromycin

Famotidine

Favipiravir

Fluvoxamine

Interferons (IFNs)
Unknown mechanism of action but hypothesized to exert antiviral activity through binding of SARS-CoV-2 spike protein [90] and potential modulation of cellular nucleotide pools, thus disrupting viral replication [91]. Identified as a potential candidate with activity against SARS-CoV-2 via computational molecular docking simulations due to its capability for spike protein binding [90]. A double-blind, RCT has been completed evaluating (atovaquone plus SOC) vs. (placebo plus SOC) with results pending (NCT04456153)

Chloroquine, hydroxychloroquine (hydroxyl analog of chloroquine) and azithromycin have shown in vitro activity against SARS-CoV-2 in infected Vero E6 cell $[92,93]$. Also believed to have immunomodulatory activity which could theoretically benefit patients with COVID19. Multiple large retrospective studies and RCTs have shown no convincing benefit of CQ or HCQ in treatment [94-96] or prophylaxis [97, 98] of COVID-19. Similarly, benefit was not demonstrated in outpatients with COVID-19 [99, 100]. The combination of CQ/HCQ with azithromycin is also associated with increased risk for cardiovascular toxicity (e.g., QTc prolongation)

Famotidine is a H2-receptor antagonist hypothesized to inhibit replication of SARS-CoV-2 by binding to its papain-like protease [101]. However, no in vitro antiviral activities were shown in SARS-CoV-2 infected Vero E6 cells [102]. A meta-analysis of five retrospective studies showed no significant protective effect of famotidine in decreasing the rates of severe illness, intubation, or death in patients with COVID-19 [103]

Favipiravir is an RNA-dependent RNA polymerase inhibitor. Not available in the USA. In an open-label, non-randomized clinical trial in China, favipiravir was associated with reduced duration of viral shedding and time to improvement of chest imaging compared to lopinavir/ ritonavir [104]. In other RCTs, favipiravir showed no significant protective effect in viral clearance [105] or time to clinical recovery [106]

Selective serotonin re-uptake inhibitor (SSRI) with several hypothesized mechanisms of action including anti-inflammatory cytokine regulation via inactivation of sigma-1 receptor activity, interference of lysosomal trafficking of SARS-CoV-2, and decreased platelet aggregation [107]. One RCT $(N=152)$ found a lower likelihood of clinical deterioration in adult outpatients with symptomatic COVID-19 treated with fluvoxamine $100 \mathrm{mg}$ three times daily for 15 days compared to placebo [108]. Observational data have shown that other SSRIs (e.g., escitalopram and fluoxetine) were associated with decreased risk of intubation or death [109]. Additional studies are needed to determine fluvoxamine's place in therapy as an antiviral or adjunct treatment for minimizing inflammatory or procoagulant effects of COVID-19

Interferons upregulate the body's natural immune system which theoretically can benefit patients with viral infections. IFN alpha and beta have shown in vitro activity against SARS-CoV-2, and IFN beta seems to produce a stronger effect on SARS-CoV-2 than on SAR-CoV-1 $[110,111]$. Clinical trial data that specifically evaluates interferon therapy in COVID-19 infection are lacking. Available trials evaluated IFNs as a component of a combination therapy. An open-label RCT showed that the combination therapy of IFN beta-1b, ribavirin, plus LPV/RTV was more effective than LPV/RTV monotherapy in shortening the time to negative SARS-CoV-2 polymerase chain reaction (PCR) results and symptom resolution in patients who had $<7$ days of symptoms [112]. Another open-label RCT in Iran among patients with severe COVID-19 illness showed significantly reduced 28-day mortality with subcutaneous interferon 1a compared to the control group [113] 
Table 1 (continued)

Ivermectin

Lopinavir with ritonavir (LPV/RTV)

Molnupiravir

Nitazoxanide
Conflicting in vitro evidence of activity against SARS-CoV-2. Several retrospective cohort studies and small RCTs have shown mixed outcomes with ivermectin. An RCT Iraq $(N=118)$ with mild to severe COVID-19 patients showed that ivermectin plus doxycycline was associated with reduced time to recovery [114], and another study conducted in Bangladesh $(N=72)$ among patients with mild COVID19 showed a faster viral clearance with ivermectin monotherapy without similar effect on clinical symptoms [115]. However, a larger RCT in Colombia among hospitalized patients with mild COVID-19, 5-day ivermectin therapy did not improve median time to resolution of symptoms compared with placebo [116]. Furthermore, the high risk of bias, lack of blinding, wide heterogeneity, and some concerns over data veracity among available RCTs with ivermectin means definitive interpretation of ivermectin's role in COVID-19 awaits larger, RCTs [117]

Lopinavir is proposed to block the main protease of SARS-CoV-1 and inhibit viral replication. An open-label RCT from China early in the pandemic suggested that LPV/RTV treatment given within 12 days from symptom onset was associated with faster recovery and lower mortality than those in the standard-of-care (SOC) group [118]. However, subsequent RCTs, including two large open-label RCTs among hospitalized patients with COVID-19, LPV/RTV was not effective in reducing the time to mortality, hospital discharge, and risk for progression to mechanical ventilation $[19,119]$

Prodrug of ribonucleoside analog beta-d-N4-hydroxycytidine which competes as a substrate for viral ribonucleic acid (RNA) polymerases, causing viral error catastrophe due to increased viral mutation beyond a biologically tolerable threshold, impairment of viral fitness [120]. In vivo data demonstrated significantly decreased SARS-CoV-2 transmission in ferret models and potent antiviral effect in human epithelial cells (half maximal inhibitory concentration $\left[\mathrm{IC}_{50}\right] 0.15 \mathrm{uM}$ ) $[121,122]$. Phase 1 and 2 data showed potential efficacy and safety in humans [120]. A phase 3 study evaluating molnupiravir for the outpatient management of COVID-19 was stopped early at interim analysis due to favorable reduction in risk of hospitalization or death, but the full results have not been peer-reviewed or published (NCT04575597) [123]. Manufacturer terminated the phase 3 portion of its study evaluating molnupiravir for hospitalized patients with COVID-19 due to lack of perceived clinical benefit [124]

Antiprotozoal drug with in vitro activity against a range of viruses (e.g., respiratory syncytial virus [RSV], hepatitis B virus [HBV], hepatitis $\mathrm{C}$ virus $[\mathrm{HCV}])$. It is hypothesized that nitazoxanide affects SARSCoV-2 entry and fusion into host cells, disrupts viral genome synthesis and translation, packaging and release of virions [125]. In vitro evidence suggests similar efficacy against SARS-CoV-2 replication in cell culture assays $\left(\mathrm{EC}_{50} 2.12 \mathrm{uM}\right)$ compared to remdesivir $\left(\mathrm{EC}_{50}\right.$ $0.77 \mathrm{uM})$ and chloroquine $\left(\mathrm{EC}_{50} 1.13 \mathrm{uM}\right)[92]$. One $\mathrm{RCT}(N=465)$ found nitazoxanide $500 \mathrm{mg}$ three times daily for 5 days for mild COVID-19 significantly reduced the viral load but showed no difference in symptom resolution compared to placebo [126]. Majority of clinical data are observational or retrospective with high risk of bias. A placebo-controlled RCT in preprint also found a significant decline in viral load in mild or moderate COVID-19 with nitazoxanide but no clinical outcomes were measured [127] 
Table 1 (continued)

Nitric oxide (NO)

Ribavirin

Ruxolitinib

Vitamin D

have persisted through to the latter half of 2020 with a high number deemed unnecessary and inappropriate. [76]

It is worth noting that patients with prolonged COVID19 hospitalizations and receipt of immunomodulatory treatments remain at risk for bacterial secondary infections, including from MDROs. Fungal secondary infections with Aspergillus or Zygomycetes have also been described in case series and observational cohort studies especially in severely ill, mechanically ventilated COVID19 patients. A wide range of incidence rates were reported (4-20\%) [77-79], warranting careful consideration of potential invasive mold infections in certain COVID-19 patients.

The inevitable diversion of ASP efforts to COVID-19 response, coupled with increases in empiric antibiotic use, may contribute to potential increases in MDROs in the future and will require a renewed focus on judicious antimicrobial prescribing [80]. However, the tremendous efforts of many ASPs during the pandemic deserve acknowledgment and further solidify their importance in healthcare systems.
Although studied in non-COVD-19 patients with acute respiratory distress syndrome (ARDS), inhaled NO has limited evidence in COVID-19. It is recommended as a rescue therapy for severe ARDS in COVID-19 patients where other options fail to improve oxygenation (weak recommendation, CIII) $[3 \bullet, 67]$. A Cochrane review of 13 trials in non-COVID-19 ARDS patients did not show a mortality benefit ( $38.2 \%$ vs. $37.5 \%, \mathrm{RR}=1.04 ; 95 \% \mathrm{CI}, 0.9$ to 1.19$)$ and only a transient improvement in oxygenation [128]

Ribavirin was not found to be effective against SARS-CoV-1 in vitro [129], and the combination of ribavirin with interferon-alpha against MERS-CoV did not reduce mortality in a multicenter observational study [130]

Janus-associated kinase (JAK) 1 and 2 inhibitor capable of suppressing cytokine signaling responsible for hyperinflammatory response and organ damage in moderate to severe COVID-19 [131]. One RCT $(N=43)$ comparing ruxolitinib to placebo found no statistical difference any clinical outcome but numerically favored ruxolitinib for faster median time to clinical improvement (12 vs. 15 days), improvement on imaging at 14 days ( $90 \%$ vs. $61.9 \%$ ), and 28 -day mortality (0\% vs. $14.3 \%$ ) [132]. Similar mechanism to baricitinib so the lack of statistical difference in the RCT may be due to small sample size

Hypothesized to play a role in ARDS [133]; Vitamin D deficiency (defined as serum 25-hydroxyvitamin D concentration $<20 \mathrm{ng} / \mathrm{mL}$ ) may be associated with higher risk of developing several infections [134]; In an open-label RCT among hospitalized patients with COVID-19 pneumonia $(N=76)$, vitamin D supplementation was associated with reduced rate of ICU admissions (vitamin D vs. SOC; $50 \%$ vs. $2 \% ; p<0.001$ ) [135]. In another double-blind, placebo-controlled RCT among hospitalized adults with moderate to severe COVID-19 $(N=240)$, vitamin D supplementation increased serum 25-hydroxyvitamin $\mathrm{D}$ concentrations but failed to improve clinical outcomes compared to placebo [136]

\section{Conclusions}

This review has summarized the current state of COVID19 therapeutic management based on available clinical trials and guidelines as of October 2021. While an extensive amount of research has already been conducted related to the treatment of this global threat, many therapies remain under investigation to define optimal COVID-19 management strategies. The most important strategy for ending the COVID-19 pandemic is the global active vaccination campaign, which is beyond the scope of this review. However, given the massive scope and challenges inherent in a global vaccination effort, clinicians must remain prepared to manage ongoing COVID-19 cases with the latest, upto-date therapies guided by the rapidly evolving treatment landscape.

Supplementary Information The online version contains supplementary material available at https://doi.org/10.1007/s11908-021-00769-8. 


\section{Compliance with Ethical Standards}

Conflict of Interest Esther Bae, James Sanders, Meagan Johns, Kevin Lin, Jessica Ortwine, Wenjing Wei, and Norman Mang declare that they have no conflict of interest.

James Cutrell reports non-financial support from the NIH, Gilead, and Regeneron from COVID-19 treatment trials outside of this work.

Human and Animal Rights and Informed Consent This article does not contain any studies with human or animal subjects performed by any of the authors.

\section{References}

Papers of particular interest, published recently, have been highlighted as: • Of importance

1. The Johns Hopkins University. COVID-19 dashboard by the Center for Systems Science and Engineering (CSSE) at Johns Hopkins University (JHU). https://coronavirus.jhu.edu/map. html. Accessed 7 October 2021.

2. Sanders JM, Monogue ML, Jodlowski TZ, Cutrell JB. Pharmacologic Treatments for Coronavirus Disease 2019 (COVID-19): A Review. JAMA. 2020;323(18):1824-36. https://doi.org/10.1001/ jama.2020.6019.

3. COVID-19 Treatment Guidelines Panel. Coronavirus Disease 2019 (COVID-19) Treatment Guidelines. National Institutes of Health. 2021. https://www.covid19treatmentguidelines.nih. gov/. Accessed 20 September 2021. The guidelines for the management of coronavirus disease 2019 developed by the US National Institutes of Health (NIH) that continue to be updated with newly emerging clinical data.

4. - World Health Organization. Novel Coronavirus (2019-nCoV) technical guidance. https://www.who.int/emergencies/diseases/ novel-coronavirus-2019/technical-guidance. Accessed 15 June 2021. The international guidelines for the management of coronavirus disease 2019 developed by the World Health Organization (WHO).

5. Gandhi RT, Lynch JB, Del Rio C. Mild or moderate Covid-19. N Engl J Med. 2020;383(18):1757-66. https://doi.org/10.1056/ NEJMcp2009249.

6. Griffin DO, Brennan-Rieder D, Ngo B, Kory P, Confalonieri M, Shapiro L, et al. The importance of understanding the stages of COVID-19 in treatment and trials. AIDS Rev. 2021;23(1):40-7. https://doi.org/10.24875/AIDSRev.200001261.

7. Jorgensen SCJ, Kebriaei R, Dresser LD. Remdesivir: Review of pharmacology, pre-clinical data, and emerging clinical experience for COVID-19. Pharmacotherapy. 2020;40(7):659-71. https://doi.org/10.1002/phar.2429.

8. Xu Y, Barauskas O, Kim C, Babusis D, Murakami E, Kornyeyev $\mathrm{D}$, et al. Off-target in vitro profiling demonstrates that remdesivir is a highly selective antiviral agent. Antimicrob Agents Chemother. 2021;65(2)e02237-e2320. https://doi.org/10.1128/AAC. 02237-20.

9. Davis MR, McCreary EK, Pogue JM. That escalated quickly: remdesivir's place in therapy for COVID-19. Infect Dis Ther. 2020;9(3):525-536. https://doi.org/10.1007/ s40121-020-00318-1.

10. Beigel JH, Tomashek KM, Dodd LE, Mehta AK, Zingman BS, Kalil AC, et al. Remdesivir for the treatment of Covid-19 - final report. N Engl J Med. 2020;383(19):1813-26. https://doi.org/ 10.1056/NEJMoa2007764.

11. Ader F, Bouscambert-Duchamp M, Hites M, Peiffer-Smadja N, Poissy J, Belhadi D, et al. Remdesivir plus standard of care versus standard of care alone for the treatment of patients admitted to hospital with COVID-19 (DisCoVeRy): a phase 3, randomised, controlled, open-label trial. Lancet Infect Dis. 2021. https://doi.org/10.1016/S1473-3099(21)00485-0.

12. Wang Y, Zhang D, Du G, Du R, Zhao J, Jin Y, et al. Remdesivir in adults with severe COVID-19: a randomised, double-blind, placebo-controlled, multicentre trial. Lancet. 2020;395(10236):156978. https://doi.org/10.1016/S0140-6736(20)31022-9.

13. Goldman JD, Lye DCB, Hui DS, Marks KM, Bruno R, Montejano $\mathrm{R}$, et al. Remdesivir for 5 or 10 days in patients with severe Covid19. N Engl J Med. 2020;383(19):1827-37. https://doi.org/10.1056/ NEJMoa2015301.

14. Spinner CD, Gottlieb RL, Criner GJ, Arribas Lopez JR, Cattelan AM, Soriano Viladomiu A, et al. Effect of remdesivir vs standard care on clinical status at 11 days in patients with moderate COVID19: a randomized clinical trial. JAMA. 2020;324(11):1048-57. https://doi.org/10.1001/jama.2020.16349.

15. Bhimraj A, Morgan RL, Shumaker AH, Lavergne V, Baden L, Cheng VC, et al. Infectious Diseases Society of America guidelines on the treatment and management of patients with COVID19. Clin Infect Dis. 2020. https://doi.org/10.1093/cid/ciaa478.

16. Lee EE, Song KH, Hwang W, Ham SY, Jeong H, Kim JH, et al. Pattern of inflammatory immune response determines the clinical course and outcome of COVID-19: unbiased clustering analysis. Sci Rep. 2021;11(1):8080. https://doi.org/10.1038/ s41598-021-87668-z.

17. Garcia LF. Immune response, inflammation, and the clinical spectrum of COVID-19. Front Immunol. 2020;11:1441. https:// doi.org/10.3389/fimmu.2020.01441.

18. Cevik M, Kuppalli K, Kindrachuk J, Peiris M. Virology, transmission, and pathogenesis of SARS-CoV-2. BMJ. 2020;371:m3862. https://doi.org/10.1136/bmj.m3862.

19. WHO Solidarity Trial Consortium. Repurposed Antiviral Drugs for Covid-19 - Interim WHO Solidarity Trial Results. N Engl J Med. 2021;384(6):497-511. https://doi.org/10.1056/NEJMoa2023184.

20. US Food and Drug Administration. FDA approves first treatment for COVID-19. https://www.fda.gov/news-events/pressannouncements/fda-approves-first-treatment-covid-19. Published May 1, 2020. Accessed June 4, 2021.

21. Weinreich DM, Sivapalasingam S, Norton T, Ali S, Gao H, Bhore R, et al. REGN-COV2, a neutralizing antibody cocktail, in outpatients with Covid-19. N Engl J Med. 2021;384(3):23851. https://doi.org/10.1056/NEJMoa2035002.

22. Gottlieb RL, Nirula A, Chen P, Boscia J, Heller B, Morris $\mathrm{J}$, et al. Effect of bamlanivimab as monotherapy or in combination with etesevimab on viral load in patients with mild to moderate COVID-19: a randomized clinical trial. JAMA. 2021;325(7):632-44. https://doi.org/10.1001/jama.2021.0202.

23. Weinreich DM, Sivapalasingam S, Norton T, Ali S, Gao H, Bhore R, et al. REGEN-COV Antibody Cocktail in Outpatients with Covid-19. medRxiv. 2021:2021.06.09.21257915. https://doi.org/10.1101/2021.06.09.21257915.

24. Weinreich DM, Sivapalasingam S, Norton T, Ali S, Gao H, Bhore R, et al. REGEN-COV Antibody Combination and Outcomes in Outpatients with Covid-19. N Engl J Med. 2021. https://doi.org/10.1056/NEJMoa2108163.

25. Dougan M, Nirula A, Azizad M, Mocherla B, Gottlieb RL, Chen $\mathrm{P}$, et al. Bamlanivimab plus etesevimab in mild or moderate Covid-19. N Engl J Med. 2021. https://doi.org/10.1056/ NEJMoa2102685. 
26. Gupta A, Gonzalez-Rojas Y, Juarez E, Casal MC, Moya J, Falci DR, et al. Early Covid-19 treatment With SARS-CoV-2 neutralizing antibody sotrovimab. medRxiv. 2021:2021.05.27.21257096. https://doi.org/10.1101/2021.05.27.21257096.

27. Horby PW, Mafham M, Peto L, Campbell M, Pessoa-Amorim G, Spata E, et al. Casirivimab and imdevimab in patients admitted to hospital with COVID-19 (RECOVERY): a randomised, controlled, open-label, platform trial. medRxiv. 2021:2021.06.15.21258542. https://doi.org/10.1101/2021.06.15. 21258542.

28. ACTIV-3/TICO LY-CoV555 Study Group. A neutralizing monoclonal antibody for hospitalized patients with covid-19. N Engl J Med. 2021;384(10):905-914. https://doi.org/10.1056/NEJMoa2033130.

29. O'Brien MP, Forleo-Neto E, Sarkar N, Isa F, Hou P, Chan K-C et al. Subcutaneous REGEN-COV antibody combination in early asymptomatic SARS-CoV-2 infection: a randomized clinical trial. medRxiv. 2021:2021.06.14.21258569. https://doi.org/10. 1101/2021.06.14.21258569.

30. Cohen MS, Nirula A, Mulligan MJ, Novak RM, Marovich M, Yen C, et al. Effect of bamlanivimab vs placebo on incidence of COVID-19 among residents and staff of skilled nursing and assisted living facilities: a randomized clinical trial. JAMA. 2021;326(1):46-55. https://doi.org/10.1001/jama.2021.8828.

31. Food and Drug Administration. Fact sheet for health care providers emergency use authorization (EUA) of bamlanivimab and etesevimab. https://www.fda.gov/media/145802/download. Accessed 14 June 2021.

32. Food and Drug Administration. Fact sheet for health care providers emergency use authorization (EUA) of casirivimab and imdevimab. https://www.fda.gov/media/145611/download. Accessed 14 June 2021.

33. Food and Drug Administration. Fact sheet for health care providers emergency use authorization (EUA) of sotrovimab. https:// www.fda.gov/media/149534/download. Accessed 14 June 2021.

34. Historical EAP program participation. https://www.uscovidplasma. org/. Accessed 15 June 2021.

35. Joyner MJ, Carter RE, Senefeld JW, Klassen SA, Mills JR, Johnson $\mathrm{PW}$, et al. Convalescent plasma antibody levels and the risk of death from Covid-19. N Engl J Med. 2021;384(11):1015-27. https://doi. org/10.1056/NEJMoa2031893.

36. Food and Drug Administration. Fact sheet for health care providers: EUA of COVID-19 convalescent plasma 2021. https:// www.fda.gov/media/141478/download. Accessed 15 June 2021.

37. Abani O, Abbas A, Abbas F, et al. Convalescent plasma in patients admitted to hospital with COVID-19 (Recovery): a randomised controlled, open-label, platform trial. The Lancet. 2021;397(10289):2049-2059. https://doi.org/10.1016/S01406736(21)00897-7.

38. Janiaud P, Axfors C, Schmitt AM, Gloy V, Ebrahimi F, Hepprich $\mathrm{M}$, et al. Association of convalescent plasma treatment with clinical outcomes in patients with COVID-19: a systematic review and meta-analysis. JAMA. 2021;325(12):1185-95. https://doi. org/10.1001/jama.2021.2747.

39. Libster R, Perez Marc G, Wappner D, Coviello S, Bianchi A, Braem V, et al. Early High-titer plasma therapy to prevent severe Covid-19 in older adults. N Engl J Med. 2021;384(7):610-8. https://doi.org/10.1056/NEJMoa2033700.

40. Joyner MJ, Bruno KA, Klassen SA, Kunze KL, Johnson PW, Lesser ER, et al. Safety update: COVID-19 convalescent plasma in 20,000 hospitalized patients. Mayo Clin Proc. 2020;95(9):188897. https://doi.org/10.1016/j.mayocp.2020.06.028.

41. Wiersinga WJ, Rhodes A, Cheng AC, Peacock SJ, Prescott HC. Pathophysiology, transmission, diagnosis, and treatment of coronavirus disease 2019 (COVID-19): a review. JAMA. 2020;324(8):782-93. https://doi.org/10.1001/jama.2020.12839.
42. Dobesh PP, Trujillo TC. Coagulopathy, venous thromboembolism, and anticoagulation in patients with COVID-19. Pharmacotherapy. 2020;40(11):1130-51. https://doi.org/10.1002/phar.2465.

43. - The RECOVERY Collaborative Group. Dexamethasone in hospitalized patients with covid-19. N Engl J Med. 2021;384(8):693704. https://doi.org/10.1056/NEJMoa2021436. A paradigmshifting coronavirus disease 2019 trial that demonstrated a significant mortality reduction with dexamethasone (compared to standard of care) especially in those requiring mechanical ventilation or supplemental oxygen.

44. The WHO Rapid Evidence Appraisal for COVID-19 Therapies (REACT) Working Group, Sterne JAC, Murthy S, et al. Association between administration of systemic corticosteroids and mortality among critically ill patients with covid-19: a meta-analysis. JAMA. 2020;324(13):1330. https://doi.org/10.1001/jama.2020. 17023.

45. Ramakrishnan S, Nicolau DV Jr, Langford B, Mahdi M, Jeffers $\mathrm{H}$, Mwasuku C, et al. Inhaled budesonide in the treatment of early COVID-19 (STOIC): a phase 2, open-label, randomised controlled trial. Lancet Respir Med. 2021. https://doi.org/10. 1016/S2213-2600(21)00160-0.

46. Hermine O, Mariette X, Tharaux PL, Resche-Rigon M, Porcher $\mathrm{R}$, Ravaud $\mathrm{P}$, et al. Effect of tocilizumab vs usual care in adults hospitalized with COVID-19 and moderate or severe pneumonia: a randomized clinical trial. JAMA Intern Med. 2021;181(1):32_ 40. https://doi.org/10.1001/jamainternmed.2020.6820.

47. Rosas IO, Brau N, Waters M, Go RC, Hunter BD, Bhagani S, et al. Tocilizumab in hospitalized patients with severe Covid-19 pneumonia. N Engl J Med. 2021;384(16):1503-16. https://doi. org/10.1056/NEJMoa2028700.

48. Salama C, Han J, Yau L, Reiss WG, Kramer B, Neidhart JD, et al. Tocilizumab in patients hospitalized with Covid-19 pneumonia. N Engl J Med. 2021;384(1):20-30. https://doi.org/10. 1056/NEJMoa2030340.

49. Salvarani C, Dolci G, Massari M, Merlo DF, Cavuto S, Savoldi $\mathrm{L}$, et al. Effect of tocilizumab vs standard care on clinical worsening in patients hospitalized with COVID-19 pneumonia: a randomized clinical trial. JAMA Intern Med. 2021;181(1):24-31. https://doi.org/10.1001/jamainternmed.2020.6615.

50. Stone JH, Frigault MJ, Serling-Boyd NJ, Fernandes AD, Harvey L, Foulkes AS, et al. Efficacy of tocilizumab in patients hospitalized with Covid-19. N Engl J Med. 2020;383(24):2333-44. https://doi.org/10.1056/NEJMoa2028836.

51. Veiga VC, Prats JAGG, Farias DLC, Rosa RG, Dourado LK, Zampieri FG, et al. Effect of tocilizumab on clinical outcomes at 15 days in patients with severe or critical coronavirus disease 2019: randomised controlled trial. BMJ. 2021;372: n84. https:// doi.org/10.1136/bmj.n84.

52. Abani O, Abbas A, Abbas F, et al. Tocilizumab in patients admitted to hospital with COVID-19 (Recovery): a randomised, controlled, open-label, platform trial. The Lancet. 2021;397(10285):1637-1645.

53. The REMAP-CAP Investigators. Interleukin-6 receptor antagonists in critically ill patients with covid-19. N Engl J Med. 2021;384(16):1491-1502. https://doi.org/10.1056/NEJMoa2100433.

54. Lescure FX, Honda H, Fowler RA, Lazar JS, Shi G, Wung P, et al. Sarilumab in patients admitted to hospital with severe or critical COVID-19: a randomised, double-blind, placebo-controlled, phase 3 trial. Lancet Respir Med. 2021;9(5):522-32. https://doi. org/10.1016/S2213-2600(21)00099-0.

55. Lewis TC, Adhikari S, Tatapudi V, Holub M, Kunichoff D, Troxel $\mathrm{AB}$, et al. A propensity-matched cohort study of tocilizumab in patients with coronavirus disease 2019. Crit Care Explor. 2020;2(11): e0283. https://doi.org/10.1097/CCE.0000000000000283. 
56. Jorgensen SCJ, Tse CLY, Burry L, Dresser LD. Baricitinib: a review of pharmacology, safety, and emerging clinical experience in COVID-19. Pharmacotherapy. 2020;40(8):843-56. https://doi.org/10.1002/phar.2438.

57. Kalil AC, Patterson TF, Mehta AK, Tomashek KM, Wolfe CR, Ghazaryan V, et al. Baricitinib plus remdesivir for hospitalized adults with Covid-19. N Engl J Med. 2021;384(9):795-807. https://doi.org/10.1056/NEJMoa2031994.

58. - Marconi VC, Ramanan AV, de Bono S, Kartman CE, Krishnan $\mathrm{V}$, Liao R, et al. Efficacy and safety of baricitinib for the treatment of hospitalised adults with COVID-19 (COV-BARRIER): a randomised, double-blind, parallel-group, placebo-controlled phase 3 trial. Lancet Respir Med. 2021. https://doi.org/10.1016/ S2213-2600(21)00331-3. A placebo-controlled randomized controlled trial that demonstrated a mortality benefit with baricitinib (with standard of care) especially in those who are on high-flow oxygen or non-invasive ventilation.

59. INSPIRATION Investigators, Mazloomzadeh S, Khaleghparast $\mathrm{S}$, et al. Effect of intermediate-dose vs standard-dose prophylactic anticoagulation on thrombotic events, extracorporeal membrane oxygenation treatment, or mortality among patients with covid-19 admitted to the intensive care unit: the inspiration randomized clinical trial. JAMA. 2021;325(16):1620.

60. Perepu US, Chambers I, Wahab A, Ten Eyck P, Wu C, Dayal $\mathrm{S}$, et al. Standard prophylactic versus intermediate dose enoxaparin in adults with severe COVID-19: A multi-center, open-label, randomized controlled trial. J Thromb Haemost. 2021;19(9):2225-34. https://doi.org/10.1111/jth.15450.

61. The REMAP-CAP, ACTIV-4a, and ATTACC Investigators. Therapeutic anticoagulation with heparin in critically ill patients with covid-19. N Engl J Med. 2021;385(9):777-789.

62. The ATTACC, ACTIV-4a, and REMAP-CAP Investigators. Therapeutic anticoagulation with heparin in noncritically ill patients with covid-19. N Engl J Med. 2021;385(9):790-802.

63. Lopes RD, de Barros ESPGM, Furtado RHM, Macedo AVS, Bronhara B, Damiani LP, et al. Therapeutic versus prophylactic anticoagulation for patients admitted to hospital with COVID-19 and elevated D-dimer concentration (ACTION): an open-label, multicentre, randomised, controlled trial. Lancet. 2021;397(10291):2253-63. https://doi.org/10.1016/S0140-6736(21)01203-4.

64. Sholzberg M, Tang GH, Rahhal H, AlHamzah M, Kreuziger LB, Ni Ainle F, et al. Heparin for moderately ill patients with Covid19. medRxiv. 2021. https://doi.org/10.1101/2021.07.08.21259351.

65. Talasaz AH, Sadeghipour P, Kakavand H, Aghakouchakzadeh M, Kordzadeh-Kermani E, Van Tassell BW, et al. Recent Randomized trials of antithrombotic therapy for patients with COVID-19: JACC state-of-the-art review. J Am Coll Cardiol. 2021;77(15):1903-21. https://doi.org/10.1016/j.jacc.2021.02.035.

66. Horby PW, Pessoa-Amorim G, Staplin N, Emberson JR, Campbell M, Spata E, et al. Aspirin in patients admitted to hospital with COVID-19 (RECOVERY): a randomised, controlled, open-label, platform trial. medRxiv. 2021:2021.06.08.21258132. https://doi. org/10.1101/2021.06.08.21258132.

67. Alhazzani W, Evans L, Alshamsi F, Moller MH, Ostermann M, Prescott HC, et al. Surviving sepsis campaign guidelines on the management of adults with coronavirus disease 2019 (COVID19) in the ICU: first update. Crit Care Med. 2021;49(3):e219-34. https://doi.org/10.1097/CCM.0000000000004899.

68. Munshi L, Del Sorbo L, Adhikari NKJ, Hodgson CL, Wunsch $\mathrm{H}$, Meade MO, et al. Prone position for acute respiratory distress syndrome. a systematic review and meta-analysis. Ann Am Thorac Soc. 2017;14(Supplement_4):S280-S8. https://doi.org/ 10.1513/AnnalsATS.201704-343OT.

69. Guerin C, Reignier J, Richard JC, Beuret P, Gacouin A, Boulain $\mathrm{T}$, et al. Prone positioning in severe acute respiratory distress syndrome. N Engl J Med. 2013;368(23):2159-68. https://doi. org/10.1056/NEJMoa1214103.

70. Touchon F, Trigui Y, Prud'homme E, Lefebvre L, Giraud A, Dols AM, et al. Awake prone positioning for hypoxaemic respiratory failure: past, COVID-19 and perspectives. Eur Respir Rev. 2021;30(160). https://doi.org/10.1183/16000617.0022-2021.

71. Barlam TF, Cosgrove SE, Abbo LM, MacDougall C, Schuetz AN, Septimus EJ, et al. Implementing an antibiotic stewardship program: guidelines by the Infectious Diseases Society of America and the Society for Healthcare Epidemiology of America. Clin Infect Dis. 2016;62(10):e51-77. https://doi.org/10.1093/cid/ciw118.

72. Mazdeyasna H, Nori P, Patel P, Doll M, Godbout E, Lee K, et al. Antimicrobial stewardship at the core of COVID-19 response efforts: implications for sustaining and building programs. Curr Infect Dis Rep. 2020;22(9):23. https://doi.org/10.1007/ s11908-020-00734-x.

73. Vaughn VM, Gandhi TN, Petty LA, Patel PK, Prescott HC, Malani AN, et al. Empiric antibacterial therapy and communityonset bacterial coinfection in patients hospitalized with coronavirus disease 2019 (COVID-19): a multi-hospital cohort study. Clin Infect Dis. 2021;72(10):e533-41. https://doi.org/10.1093/ cid/ciaa1239.

74. Langford BJ, So M, Raybardhan S, Leung V, Westwood D, MacFadden DR, et al. Bacterial co-infection and secondary infection in patients with COVID-19: a living rapid review and meta-analysis. Clin Microbiol Infect. 2020;26(12):1622-9. https://doi.org/10.1016/j. cmi.2020.07.016.

75. Karaba SM, Jones G, Helsel T, Smith LL, Avery R, Dzintars K, et al. Prevalence of co-infection at the time of hospital admission in COVID-19 patients, a multicenter study. Open Forum Infect Dis. 2021;8(1):ofaa578. https://doi.org/10.1093/ofid/ofaa578.

76. Van Laethem J, Wuyts S, Van Laere S, Dirkx S, Seyler L, Mertens R, et al. Antibiotic prescriptions targeting bacterial respiratory infections in admitted patients with COVID-19: a prospective observational study. Infect Dis Ther. 2021. https:// doi.org/10.1007/s40121-021-00535-2.

77. Koehler P, Cornely OA, Bottiger BW, Dusse F, Eichenauer DA, Fuchs F, et al. COVID-19 associated pulmonary aspergillosis. Mycoses. 2020;63(6):528-34. https://doi.org/10.1111/myc. 13096.

78. van Arkel ALE, Rijpstra TA, Belderbos HNA, van Wijngaarden P, Verweij PE, Bentvelsen RG. COVID-19-associated pulmonary aspergillosis. Am J Respir Crit Care Med. 2020;202(1):132-5. https://doi.org/10.1164/rccm.202004-1038LE.

79. Lamoth F, Glampedakis E, Boillat-Blanco N, Oddo M, Pagani JL. Incidence of invasive pulmonary aspergillosis among critically ill COVID-19 patients. Clin Microbiol Infect. 2020;26(12):1706-8. https://doi.org/10.1016/j.cmi.2020.07.010.

80. Nori P, Szymczak W, Puius Y, Sharma A, Cowman K, Gialanella $\mathrm{P}$, et al. Emerging co-pathogens: new delhi metallo-beta-lactamase producing Enterobacterales infections in New York City COVID19 patients. Int J Antimicrob Agents. 2020;56(6): 106179. https:// doi.org/10.1016/j.ijantimicag.2020.106179.

81. O'Brien MP, Forleo-Neto E, Musser BJ, Isa F, Chan K-C, Sarkar $\mathrm{N}$, et al. Subcutaneous REGEN-COV antibody combination for Covid-19 prevention. medRxiv. 2021:2021.06.14.21258567. https://doi.org/10.1101/2021.06.14.21258567.

82. Agarwal A, Mukherjee A, Kumar G, Chatterjee P, Bhatnagar $\mathrm{T}$, Malhotra $\mathrm{P}$, et al. Convalescent plasma in the management of moderate covid-19 in adults in India: open label phase II multicentre randomised controlled trial (PLACID Trial). BMJ. 2020;371: m3939. https://doi.org/10.1136/bmj.m3939.

83. Simonovich VA, Burgos Pratx LD, Scibona P, Beruto MV, Vallone MG, Vazquez C, et al. A randomized trial of 
convalescent plasma in Covid-19 severe pneumonia. N Engl J Med. 2021;384(7):619-29. https://doi.org/10.1056/NEJMo a2031304.

84. Corral-Gudino L, Bahamonde A, Arnaiz-Revillas F, GomezBarquero J, Abadia-Otero J, Garcia-Ibarbia C, et al. Methylprednisolone in adults hospitalized with COVID-19 pneumonia : an open-label randomized trial (GLUCOCOVID). Wien Klin Wochenschr. 2021;133(7-8):303-11. https://doi.org/10.1007/ s00508-020-01805-8.

85. Jeronimo CMP, Farias MEL, Val FFA, Sampaio VS, Alexandre MAA, Melo GC, et al. Methylprednisolone as adjunctive therapy for patients hospitalized with coronavirus disease 2019 (COVID19; Metcovid): a randomized, double-blind, phase IIb, placebocontrolled trial. Clin Infect Dis. 2021;72(9):e373-81. https://doi. org/10.1093/cid/ciaa1177.

86. Tomazini BM, Maia IS, Cavalcanti AB, Berwanger O, Rosa RG, Veiga VC, et al. Effect of dexamethasone on days alive and ventilator-free in patients with moderate or severe acute respiratory distress syndrome and COVID-19: the CoDEX randomized clinical trial. JAMA. 2020;324(13):1307-16. https://doi.org/10. 1001/jama.2020.17021.

87. Dequin PF, Heming N, Meziani F, Plantefeve G, Voiriot G, Badie J, et al. Effect of hydrocortisone on 21-day mortality or respiratory support among critically ill patients with COVID19: a randomized clinical trial. JAMA. 2020;324(13):1298-306. https://doi.org/10.1001/jama.2020.16761.

88. Angus DC, Derde L, Al-Beidh F, Annane D, Arabi Y, Beane A, et al. Effect of hydrocortisone on mortality and organ support in patients with severe COVID-19: the REMAP-CAP COVID19 corticosteroid domain randomized clinical trial. JAMA. 2020;324(13):1317-29. https://doi.org/10.1001/jama.2020. 17022.

89. Chen CX, Wang JJ, Li H, Yuan LT, Gale RP, Liang Y, et al. JAK-inhibitors for coronavirus disease-2019 (COVID-19): a meta-analysis. Leukemia. 2021. https://doi.org/10.1038/ s41375-021-01266-6.

90. Ramirez-Salinas GL, Martinez-Archundia M, Correa-Basurto J, Garcia-Machorro J. Repositioning of ligands that target the spike glycoprotein as potential drugs for SARS-CoV-2 in an in silico study. Molecules. 2020;25(23). https://doi.org/10.3390/ molecules25235615.

91. Cifuentes Kottkamp A, De Jesus E, Grande R, Brown JA, Jacobs AR, Lim JK, et al. Atovaquone inhibits arbovirus replication through the depletion of intracellular nucleotides. J Virol. 2019;93(11). https://doi.org/10.1128/JVI.00389-19.

92. Wang M, Cao R, Zhang L, Yang X, Liu J, Xu M, et al. Remdesivir and chloroquine effectively inhibit the recently emerged novel coronavirus (2019-nCoV) in vitro. Cell Res. 2020;30(3):269-71. https://doi.org/10.1038/s41422-020-0282-0.

93. Touret F, Gilles M, Barral K, Nougairede A, van Helden J, Decroly E, et al. In vitro screening of a FDA approved chemical library reveals potential inhibitors of SARS-CoV-2 replication. Sci Rep. 2020;10(1):13093. https://doi.org/10.1038/s41598-020-70143-6.

94. Magagnoli J, Narendran S, Pereira F, Cummings TH, Hardin JW, Sutton SS, et al. Outcomes of hydroxychloroquine usage in United States Veterans Hospitalized with COVID-19. Med (N Y). 2020;1(1):114-27 e3. https://doi.org/10.1016/j.medj.2020.06.001.

95. Million M, Lagier JC, Gautret P, Colson P, Fournier PE, Amrane S, et al. Early treatment of COVID-19 patients with hydroxychloroquine and azithromycin: a retrospective analysis of 1061 cases in Marseille. France Travel Med Infect Dis. 2020;35: 101738. https://doi.org/10.1016/j.tmaid.2020.101738.

96. Arshad S, Kilgore P, Chaudhry ZS, Jacobsen G, Wang DD, Huitsing $\mathrm{K}$, et al. Treatment with hydroxychloroquine, azithromycin, and combination in patients hospitalized with COVID-19. Int J Infect Dis. 2020;97:396-403. https://doi.org/10.1016/j.ijid.2020.06.099.
97. Gentry CA, Humphrey MB, Thind SK, Hendrickson SC, Kurdgelashvili G, Williams RJ 2nd, et al. Long-term hydroxychloroquine use in patients with rheumatic conditions and development of SARS-CoV-2 infection: a retrospective cohort study. Lancet Rheumatol. 2020;2(11):e689-97. https://doi.org/ 10.1016/S2665-9913(20)30305-2.

98. Boulware DR, Pullen MF, Bangdiwala AS, Pastick KA, Lofgren $\mathrm{SM}$, Okafor EC, et al. A randomized trial of hydroxychloroquine as postexposure prophylaxis for Covid-19. N Engl J Med. 2020;383(6):517-25. https://doi.org/10.1056/NEJMoa2016638.

99. Mitja O, Corbacho-Monne M, Ubals M, Tebe C, Penafiel J, Tobias A, et al. Hydroxychloroquine for early treatment of adults with mild Covid-19: a randomized-controlled trial. Clin Infect Dis. 2020. https://doi.org/10.1093/cid/ciaa1009.

100. Skipper CP, Pastick KA, Engen NW, Bangdiwala AS, Abassi M, Lofgren SM, et al. Hydroxychloroquine in nonhospitalized adults with early COVID-19: a randomized trial. Ann Intern Med. 2020;173(8):623-31. https://doi.org/10.7326/M20-4207.

101. Wu C, Liu Y, Yang Y, Zhang P, Zhong W, Wang Y, et al. Analysis of therapeutic targets for SARS-CoV-2 and discovery of potential drugs by computational methods. Acta Pharm Sin B. 2020;10(5):766-88. https://doi.org/10.1016/j.apsb.2020.02.008.

102. Malone RW, Tisdall P, Fremont-Smith P, Liu Y, Huang XP, White $\mathrm{KM}$, et al. COVID-19: famotidine, histamine, mast cells, and mechanisms. Res Sq. 2020. https://doi.org/10.21203/rs.3.rs-30934/v2.

103. Sun C, Chen Y, Hu L, Wu Y, Liang M, Ayaz Ahmed M, et al. Does famotidine reduce the risk of progression to severe disease, death, and intubation for COVID-19 patients? A systemic review and meta-analysis. Dig Dis Sci. 2021. https://doi.org/10.1007/ s10620-021-06872-z.

104. Cai Q, Yang M, Liu D, Chen J, Shu D, Xia J, et al. Experimental treatment with favipiravir for COVID-19: an open-label control study. Engineering (Beijing). 2020;6(10):1192-8. https://doi.org/ 10.1016/j.eng.2020.03.007.

105. Lou Y, Liu L, Yao H, Hu X, Su J, Xu K, et al. Clinical outcomes and plasma concentrations of baloxavir marboxil and favipiravir in COVID-19 patients: an exploratory randomized, controlled trial. Eur J Pharm Sci. 2021;157: 105631. https://doi.org/10. 1016/j.ejps.2020.105631.

106. Chen C, Zhang Y, Huang J, Yin P, Cheng Z, Wu J, et al. Favipiravir versus Arbidol for COVID-19: A Randomized Clinical Trial. medRxiv. 2020:2020.03.17.20037432. https://doi.org/10.1101/ 2020.03.17.20037432.

107. Sukhatme VP, Reiersen AM, Vayttaden SJ, Sukhatme VV. Fluvoxamine: a review of its mechanism of action and its role in COVID-19. Front Pharmacol. 2021;12: 652688. https://doi.org/ 10.3389/fphar.2021.652688.

108. Lenze EJ, Mattar C, Zorumski CF, Stevens A, Schweiger J, Nicol GE, et al. Fluvoxamine vs placebo and clinical deterioration in outpatients with symptomatic COVID-19: a randomized clinical trial. JAMA. 2020;324(22):2292-300. https://doi.org/10.1001/ jama.2020.22760.

109. Hoertel N, Sanchez-Rico M, Vernet R, Beeker N, Jannot AS, Neuraz A, et al. Association between antidepressant use and reduced risk of intubation or death in hospitalized patients with COVID-19: results from an observational study. Mol Psychiatry. 2021. https://doi.org/10.1038/s41380-021-01021-4.

110. Mantlo E, Bukreyeva N, Maruyama J, Paessler S, Huang C. Antiviral activities of type I interferons to SARS-CoV-2 infection. Antiviral Res. 2020;179: 104811. https://doi.org/10.1016/j.antiv iral.2020.104811.

111. Lokugamage KG, Hage A, de Vries M, Valero-Jimenez AM, Schindewolf C, Dittmann M, et al. SARS-CoV-2 is sensitive to type I interferon pretreatment. bioRxiv. 2020. https://doi.org/10. $1101 / 2020.03 .07 .982264$. 
112. Hung IF, Lung KC, Tso EY, Liu R, Chung TW, Chu MY, et al. Triple combination of interferon beta- $1 \mathrm{~b}$, lopinavir-ritonavir, and ribavirin in the treatment of patients admitted to hospital with COVID-19: an open-label, randomised, phase 2 trial. Lancet. 2020;395(10238):1695-704. https://doi.org/10.1016/S01406736(20)31042-4.

113. Davoudi-Monfared E, Rahmani H, Khalili H, Hajiabdolbaghi M, Salehi M, Abbasian L, et al. A Randomized clinical trial of the efficacy and safety of interferon beta- $1 \mathrm{a}$ in treatment of severe COVID-19. Antimicrob Agents Chemother. 2020;64(9). https:// doi.org/10.1128/AAC.01061-20.

114. Hashim HA, Maulood MF, Rasheed AM, Fatak DF, Kabah KK, Abdulamir AS, et al. Controlled randomized clinical trial on using ivermectin with doxycycline for treating COVID-19 patients in Baghdad, Iraq. medRxiv. 2020:2020.10.26.20219345. https://doi.org/10.1101/2020.10.26.20219345.

115. Ahmed S, Karim MM, Ross AG, Hossain MS, Clemens JD, Sumiya $\mathrm{MK}$, et al. A five-day course of ivermectin for the treatment of COVID-19 may reduce the duration of illness. Int J Infect Dis. 2021;103:214-6. https://doi.org/10.1016/j.ijid.2020.11.191.

116. Lopez-Medina E, Lopez P, Hurtado IC, Davalos DM, Ramirez $\mathrm{O}$, Martinez E, et al. Effect of ivermectin on time to resolution of symptoms among adults with mild COVID-19: a randomized clinical trial. JAMA. 2021;325(14):1426-35. https://doi.org/10. 1001/jama.2021.3071.

117. Siedner MJ. Ivermectin for the treatment of COVID-19 disease: too good to pass up or too good to be true? Open Forum Infect Dis. 2021. https://doi.org/10.1093/ofid/ofab318.

118. Cao B, Wang Y, Wen D, Liu W, Wang J, Fan G, et al. A trial of lopinavir-ritonavir in adults hospitalized with severe Covid-19. N Engl J Med. 2020;382(19):1787-99. https://doi.org/10.1056/ NEJMoa2001282.

119. Horby PW, Mafham M, Bell JL, et al. Lopinavir-ritonavir in patients admitted to hospital with COVID-19 (Recovery): a randomised, controlled, open-label, platform trial. The Lancet. 2020;396(10259):1345-1352.

120. Painter WP, Holman W, Bush JA, Almazedi F, Malik H, Eraut $\mathrm{N}$, et al. Human safety, tolerability, and pharmacokinetics of molnupiravir, a novel broad-spectrum oral antiviral agent with activity against SARS-CoV-2. Antimicrob Agents Chemother. 2021. https://doi.org/10.1128/AAC.02428-20.

121. Sheahan TP, Sims AC, Zhou S, Graham RL, Pruijssers AJ, Agostini ML, et al. An orally bioavailable broad-spectrum antiviral inhibits SARS-CoV-2 in human airway epithelial cell cultures and multiple coronaviruses in mice. Sci Transl Med. 2020;12(541). https://doi.org/10.1126/scitranslmed.abb5883.

122. Cox RM, Wolf JD, Plemper RK. Therapeutic MK-4482/EIDD2801 Blocks SARS-CoV-2 transmission in ferrets. Res Sq. 2020. https://doi.org/10.21203/rs.3.rs-89433/v1.

123. Merck \& Co. Inc. Merck and Ridgeback's investigational oral antiviral molnupiravir reduced the risk of hospitalization or death by approximately 50 percent compared to placebo for patients with mild or moderate COVID-19 in positive interim analysis of phase 3 study. October 2021. https://www.merck. com/news/merck-and-ridgebacks-investigational-oral-antiviralmolnupiravir-reduced-the-risk-of-hospitalization-or-death-byapproximately-50-percent-compared-to-placebo-for-patientswith-mild-or-moderat/. Accessed September 30, 2021.

124. Merck \& Co. Inc. Merck and Ridgeback Biotherapeutics Provide Update on Progress of Clinical Development Program for Molnupiravir, an Investigational Oral Therapeutic for the Treatment of Mild-to-Moderate COVID-19. April 2021. https://www.merck. com/news/merck-and-ridgeback-biotherapeutics-provide-updateon-progress-of-clinical-development-program-for-molnupiraviran-investigational-oral-therapeutic-for-the-treatment-of-mild-tomoderate-covid-19/. Accessed June 3, 2021.

125. Lokhande AS, Devarajan PV. A review on possible mechanistic insights of Nitazoxanide for repurposing in COVID-19. Eur J Pharmacol. 2021;891: 173748. https://doi.org/10.1016/j.ejphar. 2020.173748.

126. Rocco PRM, Silva PL, Cruz FF, Junior M, Tierno P, Moura MA, et al. Early use of nitazoxanide in mild Covid-19 disease: randomised, placebo-controlled trial. Eur Respir J. 2021. https:// doi.org/10.1183/13993003.03725-2020.

127. Silva M, Espejo A, Pereyra ML, Lynch M, Thompson M, Taconelli $\mathrm{H}$, et al. Efficacy of nitazoxanide in reducing the viral load in COVID19 patients. Randomized, placebo-controlled, single-blinded, parallel group, pilot study. medRxiv. 2021:2021.03.03.21252509. https://doi. org/10.1101/2021.03.03.21252509.

128. Gebistorf F, Karam O, Wetterslev J, Afshari A. Inhaled nitric oxide for acute respiratory distress syndrome (ARDS) in children and adults. Cochrane Database Syst Rev. 2016(6):CD002787. https://doi.org/10.1002/14651858.CD002787.pub3.

129. Momattin H, Mohammed K, Zumla A, Memish ZA, AlTawfiq JA. Therapeutic options for Middle East respiratory syndrome coronavirus (MERS-CoV)-possible lessons from a systematic review of SARS-CoV therapy. Int J Infect Dis. 2013;17(10):e792-8. https://doi.org/10.1016/j.ijid.2013.07.002.

130. Arabi YM, Shalhoub S, Mandourah Y, Al-Hameed F, Al-Omari $\mathrm{A}, \mathrm{Al}$ Qasim E, et al. Ribavirin and interferon therapy for critically ill patients with middle east respiratory syndrome: a multicenter observational study. Clin Infect Dis. 2020;70(9):1837-44. https://doi.org/10.1093/cid/ciz544.

131. Yeleswaram S, Smith P, Burn T, Covington M, Juvekar A, Li Y, et al. Inhibition of cytokine signaling by ruxolitinib and implications for COVID-19 treatment. Clin Immunol. 2020;218: 108517. https://doi.org/10.1016/j.clim.2020.108517.

132. Cao Y, Wei J, Zou L, Jiang T, Wang G, Chen L, et al. Ruxolitinib in treatment of severe coronavirus disease 2019 (COVID19): a multicenter, single-blind, randomized controlled trial. J Allergy Clin Immunol. 2020;146(1):137-46 e3. https://doi.org/ 10.1016/j.jaci.2020.05.019.

133. Dancer RC, Parekh D, Lax S, D'Souza V, Zheng S, Bassford $\mathrm{CR}$, et al. Vitamin D deficiency contributes directly to the acute respiratory distress syndrome (ARDS). Thorax. 2015;70(7):61724. https://doi.org/10.1136/thoraxjnl-2014-206680.

134. Aranow C. Vitamin D and the immune system. J Investig Med. 2011;59(6):881-6. https://doi.org/10.2310/JIM.0b013e31821b8755.

135. Entrenas Castillo M, Entrenas Costa LM, Vaquero Barrios JM, Alcala Diaz JF, Lopez Miranda J, Bouillon R, et al. Effect of calcifediol treatment and best available therapy versus best available therapy on intensive care unit admission and mortality among patients hospitalized for COVID-19: A pilot randomized clinical study. J Steroid Biochem Mol Biol. 2020;203:105751. https://doi.org/10.1016/j.jsbmb.2020.105751.

136. Murai IH, Fernandes AL, Sales LP, Pinto AJ, Goessler KF, Duran CSC, et al. Effect of a single high dose of vitamin D3 on hospital length of stay in patients with moderate to severe COVID-19: a randomized clinical trial. JAMA. 2021;325(11):1053-60. https:// doi.org/10.1001/jama.2020.26848.

Publisher's Note Springer Nature remains neutral with regard to jurisdictional claims in published maps and institutional affiliations. 